\title{
A New Zero-Voltage-Transition Converter for Switched Reluctance Motor Drives
}

\author{
T.W. Ching, K.T. Chau and C.C. Chan \\ Department of Electrical and Electronic Engineering, \\ The University of Hong Kong, Pokfulam, HONG KONG
}

\begin{abstract}
Firstly, a new zero-voltage-transition (ZVT) converter for switched reluctance motor drives is presented. The proposed ZVT converter possesses the definite advantages that both main transistors and diodes can operate with zero-voltage switching (ZVS), unity device voltage and current stresses. Secondly, its zero-current counterpart is also presented, which offers both the main and auxiliary switches operating with zero-current switching (ZCS) and minimum current / voltage stress. They both have simple circuit topology, minimum component count and low cost. This family of converters is especially advantageous for switched reluctance motor drives demanding efficient regenerative braking, such as electric vehicle application.
\end{abstract}

\section{INTRODUCTION}

The switched reluctance motor (SRM) drive is a kind of brushless motor drives, without any rotor conductors nor permanent magnets. The SRM operates on the force of magnetic attraction with the simplest configuration compared with the other types of brushless motors. The SRM drive has some definite advantages for electric vehicle propulsion - simplest and most reliable construction, high efficiency over wide speed and torque ranges, high starting torque and low starting power, fully controllable four-quadrant operation and fast dynamic response.

Within the last decade, the research and development on SRM drives have been focused on the motor topology design and optimization as well as the motor control strategies. Nevertheless, a number of converter topologies for SRM drives have also been proposed [1]. However, most of these converter topologies employ the hard-switching technique which causes high switching losses and severe electromagnetic interference (EMI).

Recently, a number of soft-switching techniques, providing zero-voltage switching (ZVS) or zero-current switching (ZCS) condition, have been successfully developed for switched-mode power supplies (SMPS) [2]-[6]. Surprisingly, the development of soft-switching converters for $\mathrm{dc}$ and SRM drives has been very little. Even so, it has been assumed that those being developed for SMPS can be directly applicable [7]. Until recently, a few studies on soft-switching converters for $\mathrm{dc}$ and SRM drives have been carried out [8]-[11].

In this paper, a new soft-switching pulse-widthmodulated converter, namely the zero-voltage-transition (ZVT) type, as well as its zero-current counterpart, namely the zero-current-transition (ZCT) type are proposed for SRM drives. This family of converters possesses some definite advantages over its PWM counterpart and other soft-switching converters. For the ZVT converter, ZVS can be achieved for all main switches and diodes, with unity device voltage and current stresses, as well as wide operating range. For the ZCT converter, both the main and auxiliary switches can operate with ZCS and minimum voltage / current stress. They both have simple circuit topology, minimum hardware count, and low cost, leading to achieve high switching frequency, high power density and high efficiency.

Fig. 1 shows the circuit diagram of a conventional hard-switching $(n+1)$-switch converter for SRM drives. The upper chopping switch $S_{m}$ serves all three phases while the lower commutating switches $S_{1}, S_{2}$ and $S_{3}$ commutate the phases by selecting one phase at a time sequentially. For example, in Fig. 2(a), phase-1 is selected by turning on $S_{1}$ and the phase-1 current is controlled by switching $S_{\mathrm{m}}$. After a desired time, in Fig. 2(b), $S_{m}$ is turned off and the phase-1 current is freewheeling by $D_{m}$. Then, in Fig. 2(c), $S_{1}$ is turned off and energy returns to the source through $D_{m}$ and $D_{1}$. The SRM can be operated at regeneration simply by retarding the firing angles in such a way that the phase winding conduction period comes after the aligned position.

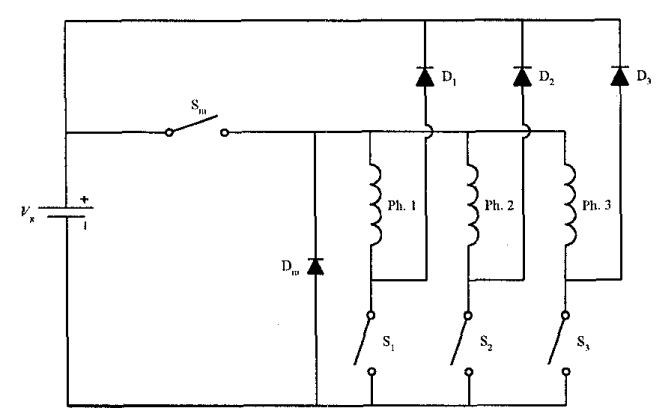

Fig. 1. Conventional converter for SRM drives. 


\section{PRINCIPLE OF OPERATION OF ZVT-SRM DRIVES}

To achieve ZVT operation, two resonant tanks are added to form the proposed ZVT converter for SRM drives shown in Fig. 3. A resonant inductor $\mathrm{L}_{\mathfrak{a}}$, a resonant capacitor $C_{a}$, an auxiliary switch $S_{a}$ and a diode $\mathrm{D}_{\mathrm{a}}$ are added to the chopping switch $\mathrm{S}_{\mathrm{m}}$. A resonant inductor $\mathrm{L}_{b}$, three resonant capacitors $\mathrm{C}_{b 1-3}$, an auxiliary switch $S_{b}$ and four diodes $D_{b}$ and $D_{b 1-3}$ are added to the commutating switches $S_{1-3}$.

A simplified one-phase circuit diagram is shown in Fig. 4. $S_{m}, D_{m}, V_{g}$ and the phase winding can be treated as a buck converter while $S_{1}, D_{1}, V_{g}$ and the phase winding can be treated as a boost converter. The equivalent circuits and operating waveforms are shown in Figs. 5 to 8, respectively. As shown in Figs. 5 and 7, there are seven operating stages within one switching cycle, which are briefly described as follows. (a)

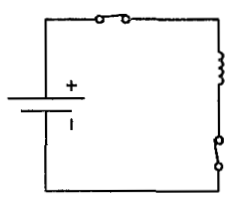

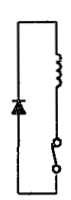

(b)

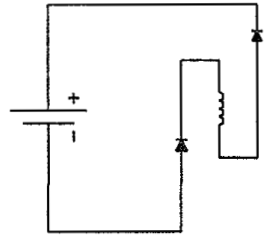

(c)
Fig. 2. Conduction modes for one phase.

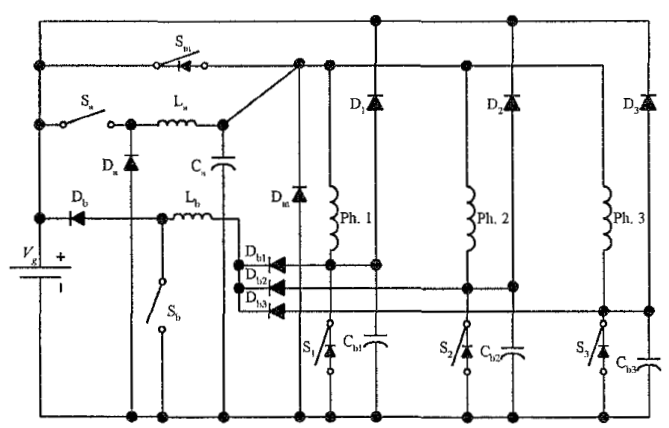

Fig. 3. Proposed ZVT converter for SRM drives.

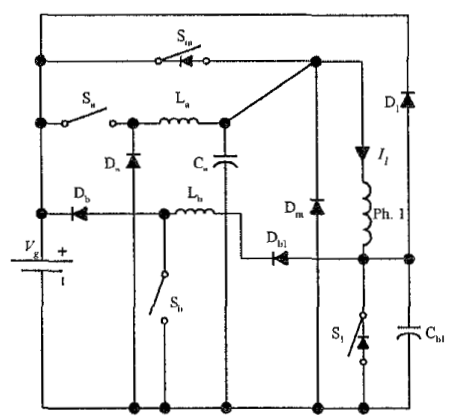

Fig. 4. Simplified one-phase circuit diagram.

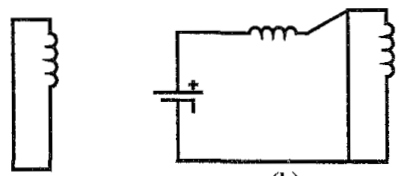

(b)

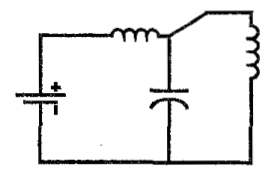

(c)

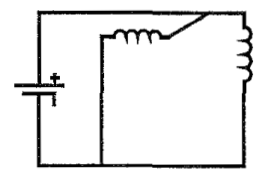

(e)

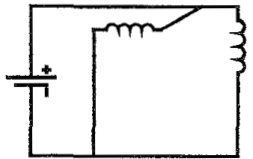

(d)

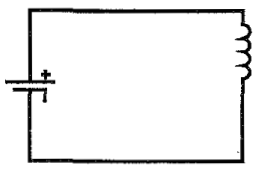

(f)

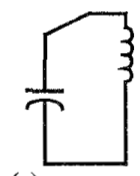

(g)

Fig. 5. Equivalent circuit for ZVT operation of $S_{m}$ and $D_{m}$.

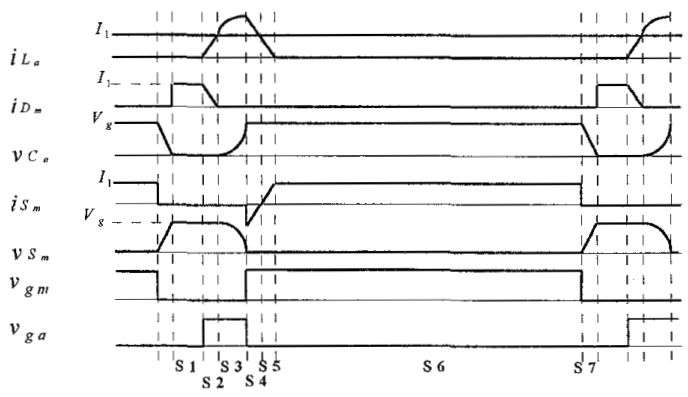

Fig. 6. Key waveforms for $S_{\mathrm{n}}$ and $\mathrm{D}_{\mathrm{n}}$

2.1 ZVT Operation of $S_{m}$ and $D_{m}$ with $L_{a}, C_{a}, S_{a}$ and $\mathrm{D}_{\mathrm{a}}$. (Figs. $5 \& 6$ )

(a) Stage $1\left[T_{0}-T_{1}\right]$ : It is a freewheeling mode via $\mathrm{D}_{\mathrm{m}}$.

(b) Stage $2\left[T_{1}-T_{2}\right]: \mathrm{S}_{\mathrm{a}}$ is turned on. $i_{L_{\mathrm{a}}}$ increases according to the slope of $V_{g} / L_{a}$.

(c) Stage $3\left[T_{2}-T_{3}\right]$ : When $i_{L_{a}}=I 1, \mathrm{D}_{\mathrm{m}}$ is turned off with ZVS, and $\mathrm{L}_{\mathrm{a}}$ and $\mathrm{C}_{\mathrm{a}}$ start resonating. 
(d) Stage $4\left[T_{3}-T_{4}\right]$ : When $v_{c}$ reaches $V_{g}, \mathrm{~S}_{\mathrm{m}}$ is turned on with ZVS. $S_{a}$ is turned off to recover the stored energy in La to the source. Then $i_{L_{a}}$ flows through $\mathrm{D}_{\mathrm{a}}$ and decreases linearly with a slope of $V_{g} / L_{a}$

(e) Stage $5\left[T_{4}-T_{5}\right]: \quad i_{L_{a}}$ keeps decreasing while $i_{S_{m}}$ increasing until $i_{L_{a}}$ reaches zero at $T_{5}$ and $\mathrm{D}_{\mathrm{a}}$ becomes off.

(f) Stage $6\left[T_{5}-T_{6}\right]$ : It is a powering mode.

(g) Stage $7\left[T_{6}-T_{7}\right]: I_{1}$ discharges $\mathrm{C}_{\mathrm{a}}$ linearly with a slope of $I_{l} / C_{a}$ until $v_{C_{a}}$ equals zero at $T_{7}$, and eventually $\mathrm{D}_{\mathrm{m}}$ becomes conducting.

2.2 ZVT Operation of $S_{1}$ and $D_{1}$ with $L_{b}, C_{b}, S_{b}, D_{b}$ and $\mathrm{D}_{\mathrm{b} 1}$. (Figs. 5 \& 6)

(a) Stage $1\left[T_{0}-T_{1}\right]: \quad D_{1}$ is conducting, a regenerating mode.

(b) Stage $2\left[T_{1}-T_{2}\right]: \mathrm{S}_{\mathrm{b}}$ is turned on. $i_{L_{b}}$ increases with the slope of $V_{g} / L_{b}$.

(c) Stage $3\left[T_{2}-T_{3}\right]$ : When $i_{L_{b}}$ reaches $I_{1}$ at $T_{2}, \mathrm{D}_{1}$ is turned off with ZVS, and $\mathrm{L}_{b}$ and $\mathrm{C}_{b}$ start resonating.

(d) Stage $4\left[T_{3}-T_{4}\right]$ : When $v_{C_{b}}$ reaches zero, $\mathrm{S}_{1}$ is turned on with ZVS. $S_{b}$ is turned off to recover the stored energy in $\mathrm{L}_{\mathrm{b}}$ to the source. Then $i_{L_{h}}$ flows through $\mathrm{D}_{b}$ and $\mathrm{D}_{\mathrm{b} 1}$ and decreases linearly.

(e) Stage $5\left[T_{4}-T_{5}\right]: i_{L_{b}}$ keeps decreasing and $i_{S_{1}}$ increasing until $i_{L_{h}}$ reaches zero at $T_{5} . \mathrm{D}_{\mathrm{b}}$ and $\mathrm{D}_{\mathrm{b} 1}$ becomes off.

(f) Stage $6\left[T_{5}-T_{6}\right]:$ It is a freewheeling mode.

(g) Stage $7\left[T_{6}-T_{7}\right]: \quad I_{I}$ charges $\mathrm{C}_{\mathrm{b}}$ linearly with a slope of $I_{l} / C_{b}$ until $v_{C_{b}}$ equals $V_{g}$ at $T_{7}$, and eventually $\mathrm{D}_{1}$ becomes conducting.

\section{PRINCIPLE OF OPERATION OF ZCT-SRM DRIVES}

To achieve ZCT operation, two resonant tanks are added to form the proposed ZCT converter for SRM drives shown in Fig. 9. A resonant inductor $L_{a}$, a resonant capacitor $C_{a}$, an auxiliary switch $S_{a}$ and a diode $\mathrm{D}_{\mathrm{a}}$ are added to the chopping switch $\mathrm{S}_{\mathrm{m}}$. A resonant inductor $L_{b}$, a resonant capacitors $C_{b}$, a diode $D_{b}$, and four auxiliary switches $S_{b}$ and $S_{b 1-3}$ are added to the commutating switches $S_{1-3}$.

A simplified one-phase circuit diagram is shown in Fig. 10. $\mathrm{S}_{\mathrm{m}}, \mathrm{D}_{\mathrm{m}}, \mathrm{V}_{\mathrm{g}}$ and the phase winding can be treated as a buck converter while $S_{1}, D_{1}, V_{g}$ and the phase winding can be treated as a boost converter. The equivalent circuits and operating waveforms are shown in Figs. 11 to 14 , respectively.
It should be noted that although the necessary hardware component for achieving the ZCT operation is similar to that for zero-voltage transition (ZVT), their hardware configurations, principles of operation, equivalent circuits as well as operating waveforms and characteristics are very different. As shown in Figs. 11 and 13 , there are nine operating stages within one switching cycle, which are briefly described as follows.

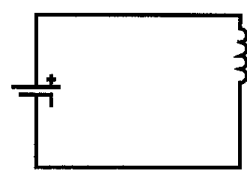

(a)

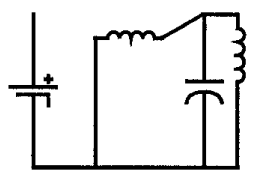

(c)

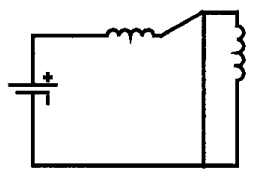

(e)

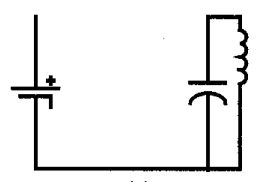

(g)

Fig. 7. Equivalent circuit for ZVT operation of $S_{1}$ and $D_{1}$.

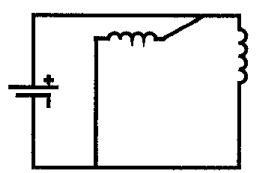

(b)

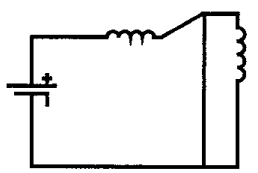

(d)

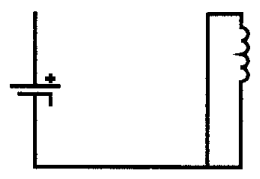

(f)

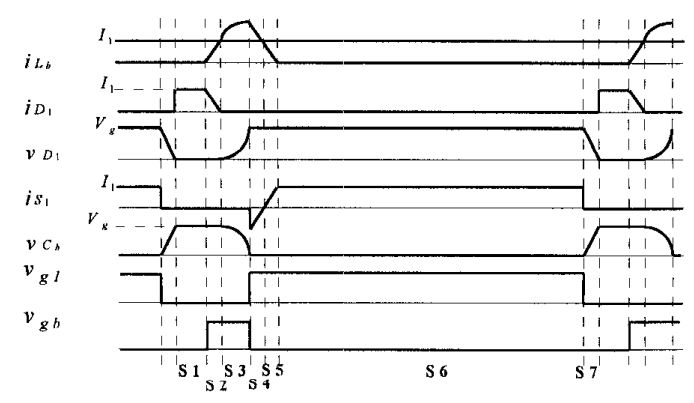

Fig. 8. Key waveforms for $S_{1}$ and $D_{1}$. 


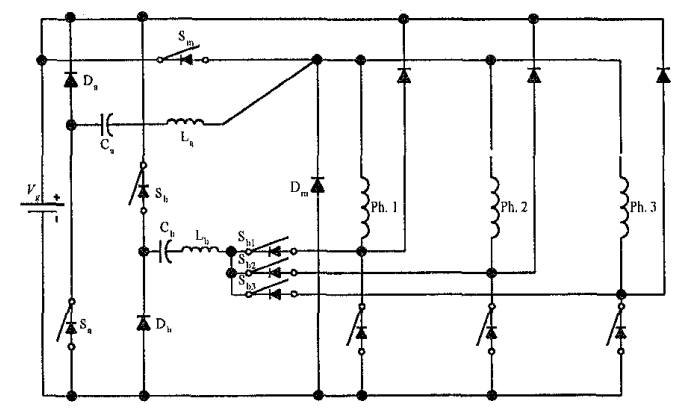

Fig. 9. Proposed ZCT converter for SRM drives.

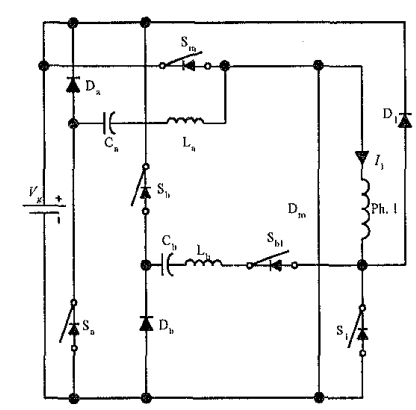

Fig. 10. Simplified one-phase circuit diagram.

3.1 ZCT Operation of $\mathrm{S}_{\mathrm{m}}$ with $\mathrm{L}_{\mathrm{a}}, \mathrm{C}_{\mathrm{a}}, \mathrm{S}_{\mathrm{a}}$ and $\mathrm{D}_{\mathrm{a}}$. (Figs. $11 \& 12)$

(a) Stage $1\left[T_{0}-T_{1}\right]: \quad \mathrm{S}_{\mathrm{a}}$ is turned on and $\mathrm{L}_{\mathrm{a}}$ and $\mathrm{C}_{\mathrm{a}}$ start resonating. When $i_{L_{a}}$ increases from zero to peak and then decreases toward zero and changes direction. $i_{L_{a}}$ reaches $-I_{1}$ at $T_{1}$ and the antiparallel diode of $\mathrm{S}_{\mathrm{a}}$ becomes on.

(b) Stage $2\left[T_{1}-T_{2}\right]: \quad \mathrm{S}_{\mathrm{a}}$ is turned off and $\mathrm{S}_{\mathrm{m}}$ is turned on with ZCS at $T_{1}$. The current of $\mathrm{D}_{\mathrm{m}}$ is directed to the auxiliary circuit. $i_{L_{a}}$ increases rapidly towards zero.

(c) Stage $3\left[T_{2}-T_{3}\right]: \quad i_{L_{a}}$ returns to zero at $T_{2}$ and the antiparallel diode of $\mathrm{S}_{\mathrm{a}}$ is turned off naturally. $\mathrm{L}_{\mathrm{a}}$ and $\mathrm{C}_{\mathrm{a}}$ continue resonating and the positive $i_{L_{a}}$ is conducted by $\mathrm{D}_{\mathrm{a}}$. $i_{L_{a}}$ returns to zero and $\mathrm{D}_{\mathrm{a}}$ is turned off naturally at $T_{3}$.

(d) Stage $4\left[T_{3}-T_{4}\right]$ : It is a powering mode.

(e) Stage $5\left[T_{4}-T_{5}\right]$ : Before $\mathrm{S}_{\mathrm{m}}$ is turned off, $\mathrm{S}_{\mathrm{a}}$ is turned on again. $\mathrm{L}_{\mathrm{a}}$ and $\mathrm{C}_{\mathrm{a}}$ start resonating. When $i_{L_{a}}$ increases from zero to peak and then decreases toward zero and changes direction and reaches $-I_{1}$ at $T_{5}$ and the antiparallel diode of $\mathrm{S}_{\mathrm{a}}$ becomes on.

(f) Stage $6\left[T_{5}-T_{6}\right]$ : At $T_{5} i_{L_{a}}$ reaches $-T_{1}$ and the current of $S_{m}$ is reduced to zero, so $S_{m}$ is turned

off with ZCS. As $i_{L_{a}}$ keeps decreasing, and flows through the antiparallel diode of $\mathrm{S}_{\mathrm{m}}$.

(g) Stage $7\left[T_{6}-T_{7}\right]:$ At $T_{6}, i_{L_{a}}$ reaches to $-I_{1}$ and the antiparallel diode of $S_{\mathrm{m}}$ stops conducting.

(h) Stage $8\left[T_{7}-T_{8}\right]:$ At $T_{7}, v_{C_{c}}$ is discharged to zero and $D_{m}$ starts to conduct. The current in $D_{m}$ increases gradually.

(i) Stage $9\left[T_{8}-T_{9}\right]$ : It is a freewheeling mode via $\mathrm{D}_{\mathrm{m}}$.

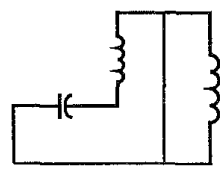

(a)

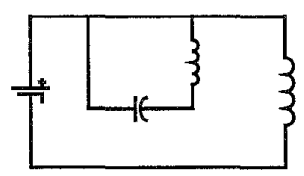

(c)

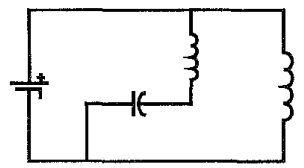

(e)

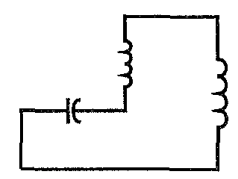

(g)

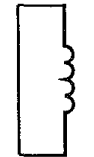

(i)

Fig. 11. Equivalent circuit for ZCT operation of $\mathrm{S}_{\mathrm{m}}$.

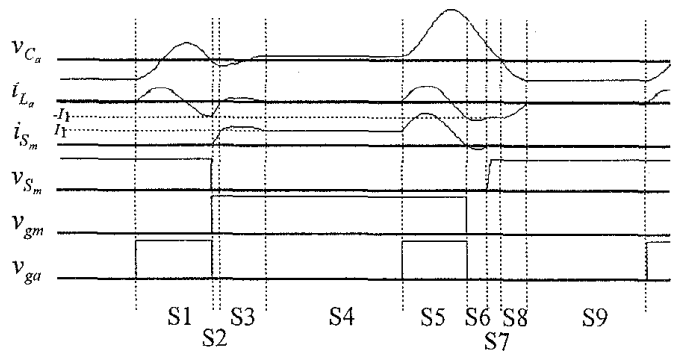

Fig. 12. Key waveforms for $\mathrm{S}_{\mathrm{m}}$. 
3.2 ZCT Operation of $\mathrm{S}_{1}$ with $\mathrm{L}_{b}, \mathrm{C}_{\mathrm{b}}, \mathrm{S}_{\mathrm{b}}$ and $\mathrm{S}_{\mathrm{b} 1}$. (Figs. $13 \& 14)$

(a) Stage $1\left[T_{0}-T_{1}\right]: \quad \mathrm{S}_{\mathrm{b}}$ and $\mathrm{S}_{\mathrm{b} 1}$ are turned on and $\mathrm{L}_{\mathrm{b}}$ and $\mathrm{C}_{\mathrm{b}}$ start resonating. When $i_{L_{b}}$ decreases from zero to negative peak and then increases toward zero and changes direction. $i_{L_{b}}$ reaches $I_{1}$ at $T_{1}$ and the antiparallel diode of $S_{b}$ and $S_{b 1}$ become on.

(b) Stage $2\left[T_{1}-T_{2}\right]: \quad \mathrm{S}_{\mathrm{b}}$ and $\mathrm{S}_{\mathrm{b} 1}$ are turned off and $\mathrm{S}_{1}$ is turned on with ZCS at $T_{1}$. The current of $\mathrm{D}_{1}$ is directed to the auxiliary circuit. $i_{L,}$ decreases rapidly towards zero.

(c) Stage $3\left[T_{2}-T_{3}\right]: \quad i_{L_{b}}$ returns to zero at $T_{2}$ and the antiparallel diode of $\mathrm{S}_{\mathrm{b}}$ and $\mathrm{S}_{\mathrm{b} 1}$ are turned off naturally. $L_{b}$ and $C_{b}$ continue resonating and the negative $i_{L_{b}}$ is conducted by $\mathrm{D}_{\mathrm{b}}$ and $\mathrm{D}_{\mathrm{b} 1} \cdot i_{L_{b}}$ returns to zero and $D_{b}$ and $D_{b 1}$ are turned off naturally at $T_{3}$.

(d) Stage $4\left[T_{3}-T_{4}\right]$ : It is a freewheeling mode

(e) Stage $5\left[T_{4}-T_{5}\right]$ : Before $\mathrm{S}_{1}$ is turned off, $\mathrm{S}_{\mathrm{b}}$ and $\mathrm{S}_{\mathrm{b} 1}$ are turned on again. $\mathrm{L}_{\mathrm{b}}$ and $\mathrm{C}_{\mathrm{b}}$ start resonating. When $i_{L_{b}}$ decreases from negative zero to peak and then increases toward zero and changes direction and reaches $I_{1}$ at $T_{5}$ and the antiparallel diode of $\mathrm{S}_{b}$ and $\mathrm{S}_{\mathrm{b} 1}$ become on.

(f) Stage $6\left[T_{5}-T_{6}\right]$ : At $T_{5}$ reaches $I_{1}$ and the current of $S_{1}$ is reduced to zero, so $S_{1}$ is turned off with ZCS. As $i_{L_{b}}$ keeps increasing, and flows through the antiparallel diode of $S_{1}$.

(g) Stage $7\left[T_{6}-T_{7}\right]$ : At $T_{6}, i_{L_{b}}$ falls to $I_{1}$ and the antiparallel diode of $\mathrm{S}_{1}$ stops conducting.

(h) Stage $8\left[T_{7}-T_{8}\right]:$ At $T_{7}, v_{C_{h}}$ is discharged to zero and $D_{1}$ starts to conduct. The current in $D_{1}$ increases gradually.

(i) Stage $9\left[T_{8}-T_{9}\right]$ : It is a powering mode via $D_{1}$.

\section{SIMULATION RESULTS}

The PSpice-simulated waveforms of single-pulse and chopping modes for both ZVT and ZCT converters are shown in Figs. 15 to 18 , respectively, they closely agree with those theoretical waveforms. The main switches and diodes of the proposed $Z V T$ converter $\left(S_{m}, D_{m}\right.$ and $S_{1}$, $\mathrm{D}_{1}$ ) can always maintain ZVS operation. For the proposed ZCT converter, both the main and auxiliary switches $\left(\mathrm{S}_{\mathrm{m}}, \mathrm{S}_{\mathrm{a}}, \mathrm{S}_{1}, \mathrm{~S}_{\mathrm{b}}\right.$ and $\left.\mathrm{S}_{\mathrm{b} 1}\right)$ can always operate with ZCS.

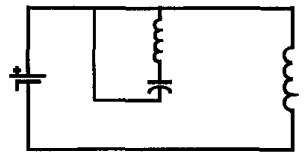

(a)

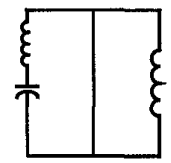

(c)

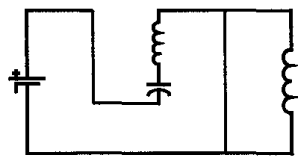

(e)

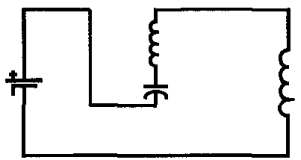

(g)

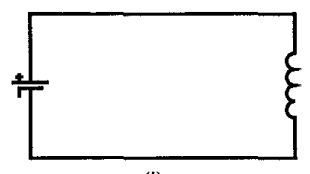

(i)

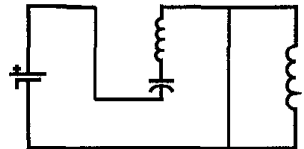

(b)

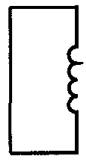

(d)

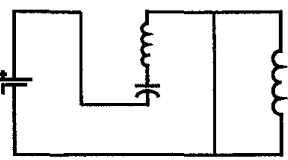

(f)

(h)

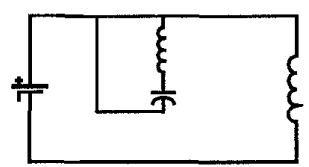

Fig. 13. Equivalent circuit for ZCT operation of $S_{1}$.

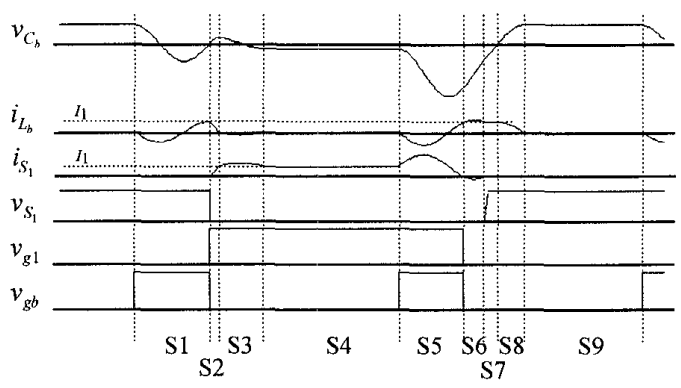

Fig. 14. Key waveforms for $S_{1}$.

\section{CONCLUSION}

A new family of soft-switching converters for SRM drives has been presented. The ZVT type possesses the definite advantages that all main switches and diodes can achieve ZVS when the corresponding device voltage and current stresses are kept at unity. On the other hand, both the main and auxiliary switches of the ZCT type can always maintain ZCS with minimum current / voltage stress. Both converters utilize a simple circuit topology, minimum hardware count and low cost, leading to achieve high power density and high efficiency. 


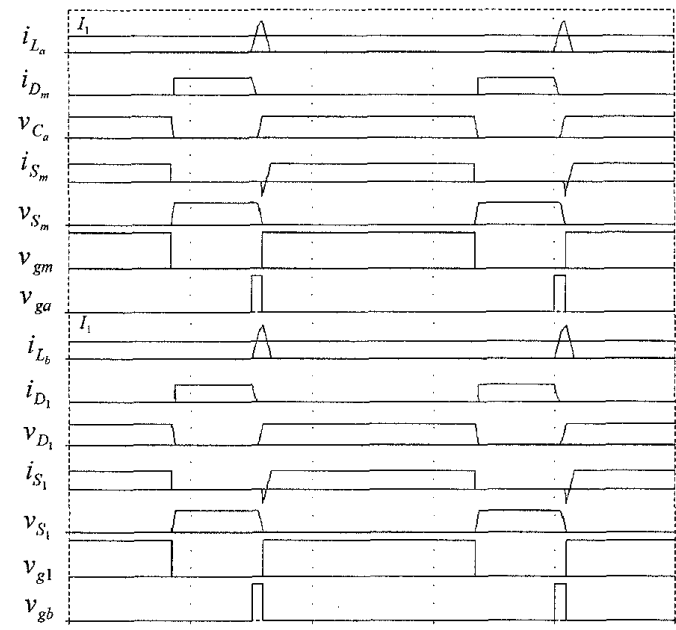

Fig. 15. PSpice simulation showing key waveforms of the ZVT converter (single-pulse mode)

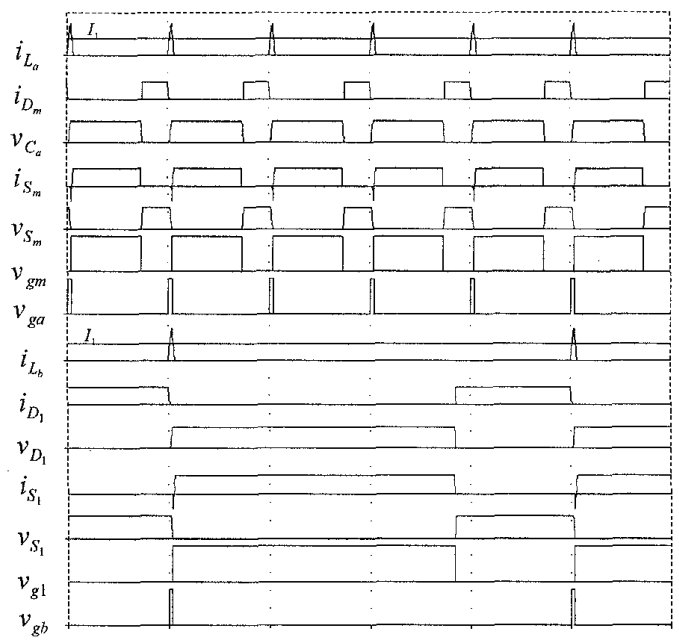

Fig. 16. PSpice simulation showing key waveforms of the ZVT converter (chopping mode).

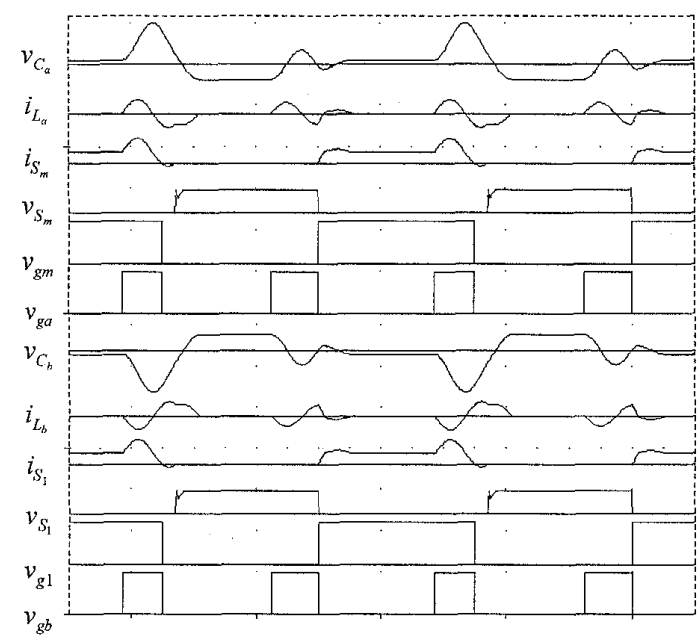

Fig. 17. PSpice simulation showing key waveforms of the ZCT converter (single-puise mode).

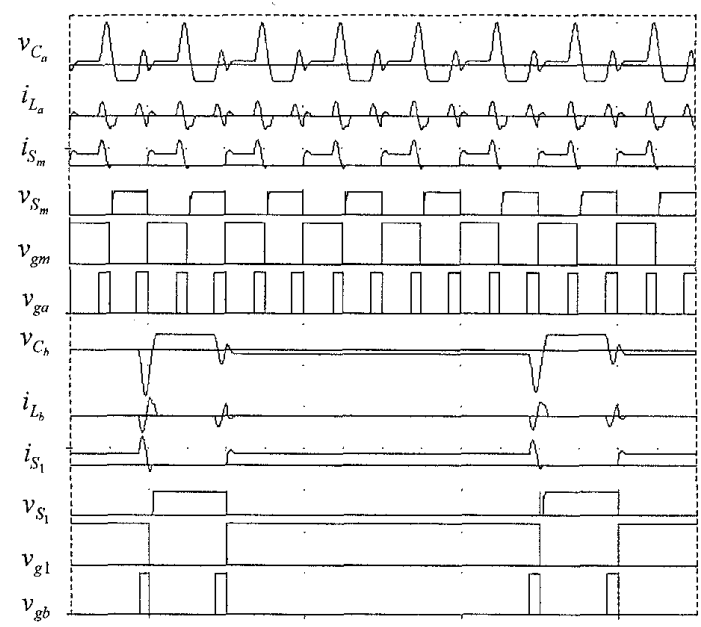

Fig. 18. PSpice simulation showing key waveforms of the ZCT converter (chopping mode)

\section{ACKNOWLEDGMENT}

This work was supported and funded in part by the Committee on Research and Conference Grants, the University of Hong Kong. 


\section{REFERENCES}

[1] T.J.E. Miller, "Switched reluctance motors and their control," Magna Physics Publishing, Oxford Science Publications.

[2] D. Maksimović and S. Cuk, "Constant-frequency control of quasi-resonant converters," IEEE Trans. Power Electron., vol. 6, 1991, pp. 141150.

[3] C.C. Chan and K.T. Chau, "A new zero-voltageswitching dc/dc boost converter," IEEE Trans. Aero. Electron. Syst., vol. 29, 1993, pp. 125-134.

[4] G. Hua, C.S. Leu and F.C. Lee, "Novel zerovoltage-transition PWM converters," In Proceedings of VPEC Power Electronics Seminar, 1991, pp. 81-88.

[5] J.G. Cho, J.W. Baek, G.H. Rim and I. Kang, "Novel zero voltage transition PWM multi-phase converters," In Proceedings of IEEE APEC, 1996, pp. 500-506.

[6] H. Mao, F.C.Y. Lee, X. Zhou, H. Dai, M. Cosan and D. Boroyevich, "Improved zero-current transition converters for high power applications," IEEE Trans. Ind. Applicat., vol. 33, 1997, pp. 1220-1231.

[7] C.C. Chong, C.Y. Chan and C.F. Foo, "A quasiresonant converter-fed dc drive system," In Proceedings of EPE, 1993, pp. 372-377.

[8] K.T. Chau, T.W. Ching and C.C. Chan, "Constant-frequency multi-resonant converter-fed dc motor drives," In Proceedings of IECON, 1996, pp. 78-83.

[9] K.T. Chau, T.W. Ching, C.C. Chan and T.W. Chan, "A Novel Soft-Switching Two-Quadrant Converter for DC Motor Drives," In Proceedings of IECON, 1997, pp. 517-522.

[10] Y. Murai, J. Cheng, and M. Yoshida, "A softswitched reluctance motor drives circuit with improved performances," In Proceedings of IEEE PESC, 1997, pp. 881-886.

[11] J.G. Cho, W.H. Kim, G.H. Rim and, K.Y. Cho, "Novel zero transition PWM converter for switched reluctance motor drives," In Proceedings of IEEE PESC, 1997, pp. 887-891. 